Western University Scholarship@Western

1978

\title{
The Theory of the Family and Intergenerational Mobility: An Empirical Test
}

George Catsiapis

Chris Robinson

Follow this and additional works at: https://ir.lib.uwo.ca/economicsresrpt

Part of the Economics Commons

Citation of this paper:

Catsiapis, George, Chris Robinson. "The Theory of the Family and Intergenerational Mobility: An Empirical Test." Department of Economics Research Reports, 7830. London, ON: Department of Economics, University of Western Ontario (1978). 


\author{
RESEARCH REPORT 7830 \\ THE THEORY OF THE FAMILY AND \\ INTERGENERATIONAL MOBILITY: \\ AN EMPIRICAL TEST \\ by \\ George Catsiapis and Chris Robinson
}

October, 1978 
THE THEORY OF THE FAMILY AND INTERGENERATIONAL MOBILITY:

AN EMPIRICAL TEST ${ }^{*}$.

George Catsiapis

University of Chicago

and

Chris Robinson

University of Western Ontario

September 1978 
In recent years economists have devoted a great deal of attention to the economics of the family. ${ }^{\prime \prime}$ It is becoming increasingly clear that further progress in such areas as labour force participation, investment in education, and the personal distribution of income requires the development of a more explicit theory of the family than was hitherto available. The purpose of this paper is to provide some empirical evidence for some aspects of family behavior hypothesized by Becker and Tomes ${ }^{2}$ in their work on the distribution of income and intergenerational mobility.

\section{The Theory}

The approach of Becker and Tomes may be summarized for the purposes of this study as follows. The utility of parents is assumed to depend on their own consumption in their generation, $z_{t}$, and on the number, $n$, and per capita income, $I_{t+1}$, of the children in the next generation. The exposition may be simplified by setting $n=1$ for each set of parents and assuming the Cobb-Douglas form for the utility function:

$$
\mathrm{U}_{t}=\mathrm{z}_{\mathrm{t}}^{1-\alpha} \mathrm{I}_{\mathrm{t}+1}^{\alpha}
$$

where $\alpha$ is interpreted as the constant fraction of the "family wealth" that: is spent on their child.

The income of the child depends on the stock of human capital the child would have in period $t+1$ in the absence of any transfers, either from parents or from other sources, called his endowment of human capita1, $E_{t+1}$, plus the increase in his human capital resulting from such transfers. Assume for simplicity that the market rate of return per unit of human capital in $t+1$ is unity, then the income of the child is given by:

$$
I_{t+1}=E_{t+1}+(1+r) Q_{t}+(1+r) G_{t}+(1+r) \gamma S_{t}
$$


where $Q_{t}$ and $G_{t}$ are dollars directly received from parental and other sources respectively, $s_{t}$ is the average per student subsidy (public and private) given to the student's college, $\gamma$ is the fraction of $s_{t}$ that the student expects to get in the form of an in-kind subsidy, and $r$ is the rate of return that he obtains by converting dollars into human capital. ${ }^{3}$ The income of the parents, $I_{t}$, may be spent either on their own consumption or transferred to their children:

$$
I_{t}=Z_{t}+Q_{t}
$$

Substituting for $Q_{t}$ from (2) we obtain:

$$
z_{t}+\frac{I_{t+1}}{1+r}=I_{t}+\frac{E_{t+1}}{1+r}+G_{t}+\gamma S_{t} \therefore W_{t}
$$

where $W_{t}$ is the present value of the family income flow over the two generations, called the parents" "social income" by Becker and Tomes. Given $E_{t+1}$, $G_{t}, r, \gamma S_{t}$, and $I_{t}$, parents are assumed to choose $Z_{t}$ and $Q_{t}$ so as to maximize (1) subject to their social income constraint (4). The result of this maximization yields the following derived demand function for $Q_{t}$ :

$$
Q_{t}=\alpha I_{t}-\frac{(1-\alpha)_{E}}{1+r}{ }_{t+1}-(1-\alpha) G_{t}-(1-\alpha) \gamma S_{t}
$$

Thus the contribution of the parent to the child 's luman capital should be positively related to the income of the parent and negatively related to the transfers the child receives from other sources and to the child's own endowment..$^{4}$ When $\mathrm{n}>1$ and all children are identical (5) bccomes:

$$
Q_{t}=: x \frac{I_{t}}{n}-\frac{(1-x)}{1+r} E_{t+1}-(1-x) G_{t}-(1-x) \gamma S_{t}
$$

where $Q_{t}, G_{t}$ and $E_{t+1}$ are transfers and endowments per child.

Since $r$ and $E_{t+1}$ are unobservable, specifications in terms of (potentially) observable variables are required in order cast (5)' in terms of 
observable variables. In this paper the endowment of a given child is . assumed to be given by:

$$
E_{t+1}=k+\phi A_{t}^{d}, \phi>0
$$

where $A_{t}^{d}$ is 'mental ability' measured in deviation form 80 that $k$ is the endowment of a child with the mean level of 'ability'. The simplest specification for $r$ is that it is a constant, and this will be taken as the maintained hypothesis for Model I. Two other models are obtained by specifying a dependence of $r$ first on 'ability' alone (Model II) and second, on 'ability', parental income and mother's education (Model III). Thus in general $r$ is given by :

$$
\frac{1}{1+r}=a+b I_{t}+c A_{t}^{d}+d M_{t}
$$

Model I specifies $b=c=d=0$. Model II specifies $b=d=0$ and $c<0$, i.e., students with higher 'ability' will translate a given dollar transfer from their parents (or outside) into a larger number of units of human capital than students with lower 'ability', ceteris paribus. Model III postulates $\mathrm{d}<0, \mathrm{c}<0$, and $\mathrm{b}<0$ which states that a given dollar transfer will be converted into more dollars in the student's consumption period, $t+1$, by a student from a wealthy background with a well-educated mother than would be the case for a student with poor and uneducated parents. The inclusion of mother's education as a determinant of $r$ is based on the assumption that it captures some components of ability not measured by $A_{t}{ }^{5}$ The income of the parents, $I_{t}$, may affect $\mathbf{r}$ via differing opportunities for investment and/or via differential tax rates implying that parents with higher tax rates incur smaller net of tax losses in transferring a dollar to the next generation. Substituting (6) and (7) into (5)' and imposing the specified restrictions yields the three alternative models. 
Under Model I we have

$$
Q_{t}=-(1-\alpha) a k-(1-\alpha) a \phi A_{t}^{d}+\alpha \frac{I_{t}}{n}-(1-\alpha) G_{t}-(1-\alpha) \gamma S_{t}
$$

Thus, Model I predicts a negative effect of $G_{t}$ and $S_{t}$ on $Q_{t}$ and a positive effect for $\left(I_{t} / n\right)$. It also predicts a negative effect for $A_{t}^{d}$ provided the common rate of return, $r$, for all individuals, exceeds minus unity. Model II states that parental transfers are given by:

$$
Q_{t}=-(1-\alpha) a k-(1-\alpha)[a \phi+c k] A_{t}^{d}+\alpha \frac{I_{t}}{n}-(1-\alpha) G_{t}-(1-\alpha) \phi c A_{t}^{d^{2}}-(1-\alpha) \gamma S_{t}
$$

As with Model $I$ a positive effect of $\left(I_{t} / n\right)$ and a negative effect of $G_{t}$ and $S_{t}$ on $Q_{t}$ is predicted. Model II however, differs from Model $I$ in two respects. First it predicts a positive effect for $A_{t}{ }^{2}$ rather than zero. Second, it predicts an ambiguous effect for $A_{t}^{d}$ since $(a \phi+c k)$ cannot be signed a priori.

Finally, under Model III parental transfers may be expressed as follows:

$$
\begin{aligned}
Q_{t}=-(1-\alpha) a k & \left.-(1-\alpha)[a \phi+k c] A_{t}^{d}+\alpha \frac{I_{t}}{n}-(1-\alpha) G_{t}-(1-\alpha) \phi c A_{t}^{d^{2}}-(1] \alpha\right) d \phi M_{t} A_{t}^{d} \\
& -(1-\alpha) \gamma S_{t}-(1-\alpha) d_{k M}-(1-\alpha) k b I_{t}-(1-\alpha) b \phi I_{t} A_{t}^{d} .
\end{aligned}
$$

This model adds several additional variables, parental income and mother's education and their interaction with 'ability'. In common with Model II, a negative effect is predicted for $G_{t}$, positive effects for $\left(I_{t} / n\right)$ and $A_{t}^{d^{2}}$, and an ambiguous effect for $A_{t}^{d}$. For the new variables a positive effect is predicted for both $M_{t}, I_{t}$ and their interactions with $A_{t}^{d}$ rather than zero as in Mode1 II.

\section{An Empirical Test}

The notion of the parents being influenced in their transfers by the total endowment (i.e., stock of human capital in the absence of parental transfers) of the child plays a central role in the Becker-Tomes analysis of 
intergenerational mobility and hence should be subjected, wherever possible, to testing. A simple, albeit imperfect, test may be made using data recently available from the U.S. National Center of Education Statistics on the financing of higher education. ${ }^{6}$ These data consist of a national probability sample of 22,532 registered high school seniors with detailed characteristics of the financing of their higher education, including grants and scholarships obtained and parental support received. ${ }^{7}$ The total amount of parental support is used as a proxy for $Q_{t} \cdot$ Information on parental income is also available to proxy $I_{t} \cdot G_{t}$ is measured by grants or scholarships obtained by the student, $S_{t}$ is measured from information (by state) on per student subsidies given to institutions of higher education, and 'ability' is measured by the results of a battery of tests administered at the time of the initial survey. 8 Model III, which contains II and I as special cases, was tested using these proxies, and the results are presented in Table I below. Variable definitions; means, and standard deviations are given in Table II:

The estimates in Table I were computed for a sample of single students who were freshmen in 1972-73. The sample was restricted to single students to avoid. the complication of the reaction of the student's family to contributions from the spouse. Dummy variables for sex, race and religion were included to test for systematic differences in contributions with respect to these characteristics. A set of regional dummy variables was also included. More than half the sample lived with their parents during their freshman year and there is a strong possibility that these students were receiving parental contributions in kind (food, lodging, etc.) which were not reported in the data. Estimates were therefore computed separately for students living 
at home and those living away. from home. If those students living at home were receiving some parental support in kind, this should be reflected in a lower constant term in their equation, where the difference between the constant terms may be interpreted as the mean value of the parental contributions in kind, received by individuals living at home. This was in fact observed, with the constant terms differing by approximately $\$ 600$. Since the equations differed almost exclusively in their constant terms the samples were pooled and a dummy variable included for individuals living at home.

A substantial number of individuals who went to college received no parental support--a substantial proportion of the observations of the dependent variable thus takes on the value zero. Assuming that the itrue' desired parental support may in many of these cases be negative, an application of ordinary least squares (OLS) will result in biased estimates. This problem was noted, and a solution offered by Tobin (1958). The results presented in Table I below include both OLS and Tobit estimates for comparison. As expected, the slope coefficients when significant are larger when the Tobit procedure is used.

\section{Interpretation of the Results and Further Work}

The results indicate that Model III is in good accord with the data, and is to be preferred to the other models. All the signs are as predicted by the theory and the results are generally highly significant by conventional standards. For a regression on individual data, the overall fit is also good. There are several reasons, however, why the procedure followed in this paper mist be regarded as a preliminary test. First, consider the relation between the theoretical variables in (10) with the proxies used in the empirical work. 
$Q_{t}$ represents the net parental transfers over the generation; $I_{t}$ represents parental income over the generation, and $G_{t}$ represents total transfers from other sources. Given accurate measures of each of these variables, the coefficient on $I_{t} / n$ would give a direct estimate of $\alpha$, the sum of the coefficients on $I_{t} / n$ and $G_{t}$ would be unity, and the ratio of the coefficients on $S_{t}$ and $G_{t}$ would yield an estimate of $\gamma$. However, the proxies differ from their theoretical counterparts in two respects. First, they all relate to a given period, rather than to the whole parental generation. $Q_{t}$ should be total parental contributions within the parental generation, rather than those given in a particular year, $I_{t}$ should be total parental income over the generation rather than income in a single period, $G_{t}$ should be total transfers from outside the family rather than the grants received in a single year, and similarly for $s_{t^{*}}$ If each proxy was proportional to its theoretical counterpart, only if the factor of proportionality was the same for all variables could direct estimates of the 'true' parameters, $\alpha$ and $\gamma$, be obtained from the cocfficient estimates. Similarly, this is the only case in which the coefficients on $\left(I_{t} / n\right)$ and $G_{t}$ would imply the same estimate for $\alpha$. The sign predictions, however, will all be preserved.

Second, the proxies may differ from their theoretical counterparts, even within a sub-period of the parental generation. For example, while contributions to college education are no doubt a major part of parental transfers, there are many forms of parental transfer, so that for some individuals parental contributions to college education will underestimate total transfers. In addition parental contributions to college education may not always be a transfer, e.g., if there is some explicit or implicit contract for the funds to be paid back at a later stage, in which case total transfers would be overestịmated. 
Despite these limitations and in view of the important role played by $\alpha$ in models of intergenerational transmission of inequality ${ }^{9}$ and by $\gamma$ in the debate over direct versus indirect subsidization of higher education $^{10}$ it appears worthwhile pursuing the implications of the estimates in Table I for the values of these parameters. By definition, $\alpha$ is the share of $W_{t}$ that the parental generation wishes the next generation to have:

$$
\alpha=\frac{\frac{1}{1+r} I_{t+1}}{W_{t}}
$$

Suppose, for example, that the rate of inflation is zero and that the parental generation wishes the per capita income of the next generation to be the proportion $\beta$ of their own then: 11

$$
\alpha=\frac{\beta}{1+r+\beta}
$$

Since $r$ is the average rate at which dollars are transferred across a genera-tion--say 25 years, and since much of the transfer will be a human capital transfer, current estimates of the rate of return to investment in education ${ }^{12}$ imply a value of $r$ perhaps as high as $800 \%$. If parents wished their offspring to have the same per capita income as they themselves have (i.e., if $\beta=1$ ) this would yield a value of around $10 \%$ for $\alpha$. Of the two estimates of $\alpha$ available from the results in Table I this "plausible benchmark value" is roughly similar to the coefficient on $I_{t} / \mathbf{n}$ but much smaller than the estimate implied by the coefficient on $G_{t}$. In fact, there is good reason for expecting the coefficient on $I_{t} / n$ to give a closer estimate for the true $\alpha_{p}$ The proxies for both $Q_{t}$ and $I_{t}$ underestimate the true variables, since parental income will be received over many years, not one, and similarly parental transfers will have taken place over many years, not just the first year of college. The 
proxies for $G_{t}$ and $S_{t}$ will also be underestimates, but much less so than those for $Q_{t}$ and $I_{t}$ since financial and in-kind transfers from outside the family are likely to be concentrated in the college period. This suggests that the coefficient on $I_{t} / n$ will give an estimate that is closer to the true value of $\alpha$ than that implied from the coefficient on $G_{t}$ and, indeed, that the latter will be a substantial overestimate since $Q_{t}$ is grossly underestimated relative to $G_{t}$.

Regarding $\gamma$, if schools were efficient and parents 8 perceptions were accurate, one dollar of in-kind subsidy should be equivalent, as far as the family is concerned, to one dollar of scholarship funds. This would imply a value of unity for $\gamma$, if $s_{t}$ was measured net of minimum administrative costs. If, on the other hand, schools were inefficient, or the subsidy was effectively bid away by non-price rationing, $\gamma$ would be zero. ${ }^{13}$ Following the arguments of the preceding section the proxies for both $G_{t}$ and $S_{t}$ underestimate the true values, but there is no strong presumption that these should be underestimates relative to one another. The implied value of $\gamma$ under the assumption of no relative underestimation is 0.72 . This would be an overestimate if $G_{t}$ was overestimated relative to $S_{t}$ and vice-versa.

In future work attention should be devoted to improving the empirical proxies, and to incorporating the additional variables, e.g., religion, into the analysis in a more satisfactory way. Coming from a Jewish background, for example, has an extraordinarily strong effect on parental transfers and merits further investigation. Indeed, the extent to which each of the 'standardizing' variables, region, religion, race, sex, etc. may be interpreted as components of a broadly defined 'endowment' should be investigated. Also, the actual parental contribution should be viewed as the outcome of two 
factors: first, the desire of parents to make transfers to their children, as represented by equation (5), and second, the optimal method of financing a student's higher education, given the optimal total level of expenditures. The equations estimated in this paper could then be viewed as the reduced form outcome of two structural equations involving $Q_{t}$, one involving a pure transfer, and the other involving simply a financing decision. Finally, the assumptions of a constant value of $r$ for each individual should be relaxed, and a dependence of $r$ on $Q_{t}$ permitted. 


\section{Footnotes}

* We are grateful to Diane Peterson for excellent computational

assistance, and to Larry Kenny, Arnold Ze1lner, Rick Barichello and members of the Workshop in Applications of Economics at the University of Chicago for comments on an earlier draft. Remaining errors are our own. This research was funded by the U.S. Office of Education, Office of Planning, Budgeting, and Evaluation, contract No. 300-78-0086.

${ }^{1}$ See Schultz (1974) for a collection of recent work on the family. 2 See Tomes (1978), Becker and Tomes (1977), (1978).

$3_{\text {This model }}$ abstracts from asset transfers.

${ }^{4}$ It might be thought that, given parental income, the higher the child's endowment--say academic ability--the more the parent may wish to invest in him. If this were true, it would come about through affecting $r$, the rate of return to the investment in the child. Holding $r$ constant, the partial effect of an increase in the child's endowment would still be negative.

${ }^{5}$ An alternative procedure would be to make test scores endogenous to the model depending on, for example, investments made prior to college. In this paper, however, $A_{t}$ is assumed exogenous. We are grateful to Larry Kenny for this point.'

6 National Longitudinal Study of the High School Class of 1972, (1976).

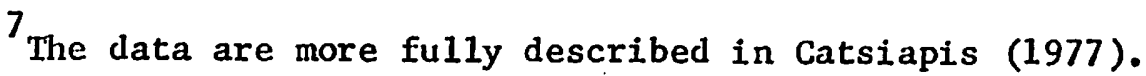

${ }^{8}$ The measure of ability was based on four test scores: vocabulary, reading, mathematics, letter groups: A sample average over the four standardized scores was used. This decision was based on a principal 
component analysis carried out by the Office of Education Statistics. This analysis. yielded a first principal component with essentially equal weights to the four tests. Also the rotated factor which explained the most common variance gave the same result. [See National Longitudinal Study of the High School Class of 1972, (1976).]

${ }^{9}$ See Becker and Tomes (1978) and Drazen (1978).

${ }^{10}$ See Mo Friedman (1968)。

${ }^{11}$ We assume for simplicity that both generations are the same size. ${ }^{12}$ See, for example, G. S. Becker, Human Capital, 2nd edition, N.B.E.R., 1975.

${ }^{13}$ See Mo McPherson (1974) for evidence of non-price rationing in public schools. 


\section{References}

Becker, G. S., Human Capital, 2nd edition, N.B.E.R., 1975. Becker, Go S. and Tomes, No, "A Theory of Intergenerational Mobility," November 1977, unpublished paper.

Becker, G. S. and Tomes, N., "A Theory of the Distribution of Income and Intergenerational Mobility," June 1968, paper presented at the Summer Meetings of the Econometric Society June 20-24, 1978 in Boulder, Colorado.

Catsiapis, G., "The Economics of Financing Investment in Higher Education," Workshop in Applications of Economics paper, University of Chicago, November 1977.

Drazen, A., "Government Debt, Human Capital, and Bequests in a Life-Cycle Mode1," Journal of Political Economy, Vol. 86, No. 3 (June 1978) pp. $505-516$.

Friedman, Milton, "The Higher Schooling in America," Public Interest, No. 11, Spring 1968, pp.108-112.

McPherson, M. S., "The Effects of Public or Private College Enrollment," unpublished Ph.D. dissertation, University of Chicago, 1974.

Schultz, T. W. (ed.), Economics of the Family: Marriage, Children and Human Capital, N.B.E.R., 1975.

Tobin, J., "Estimation of Relationships for Limited Dependent Variables," Econometrica, Vol. 26 (January 1958), pp. 24-36.

Tomes, N., "A Model of Child Endowments, and the Quality and Quantity of Children," unpublished Ph.D. dissertation, University of Chicago, 1978 .

U.S. Office of Education Statistics, National Longitudinal Study of the High Schoo1 Class of 1972, (July 1976). 
TABJES I

OLS AND TOBIT RESULISS FOR SINGLE STUDENTS ENROLLED IN POSTSECONDARY INSTITUTIONS IN 1972-73

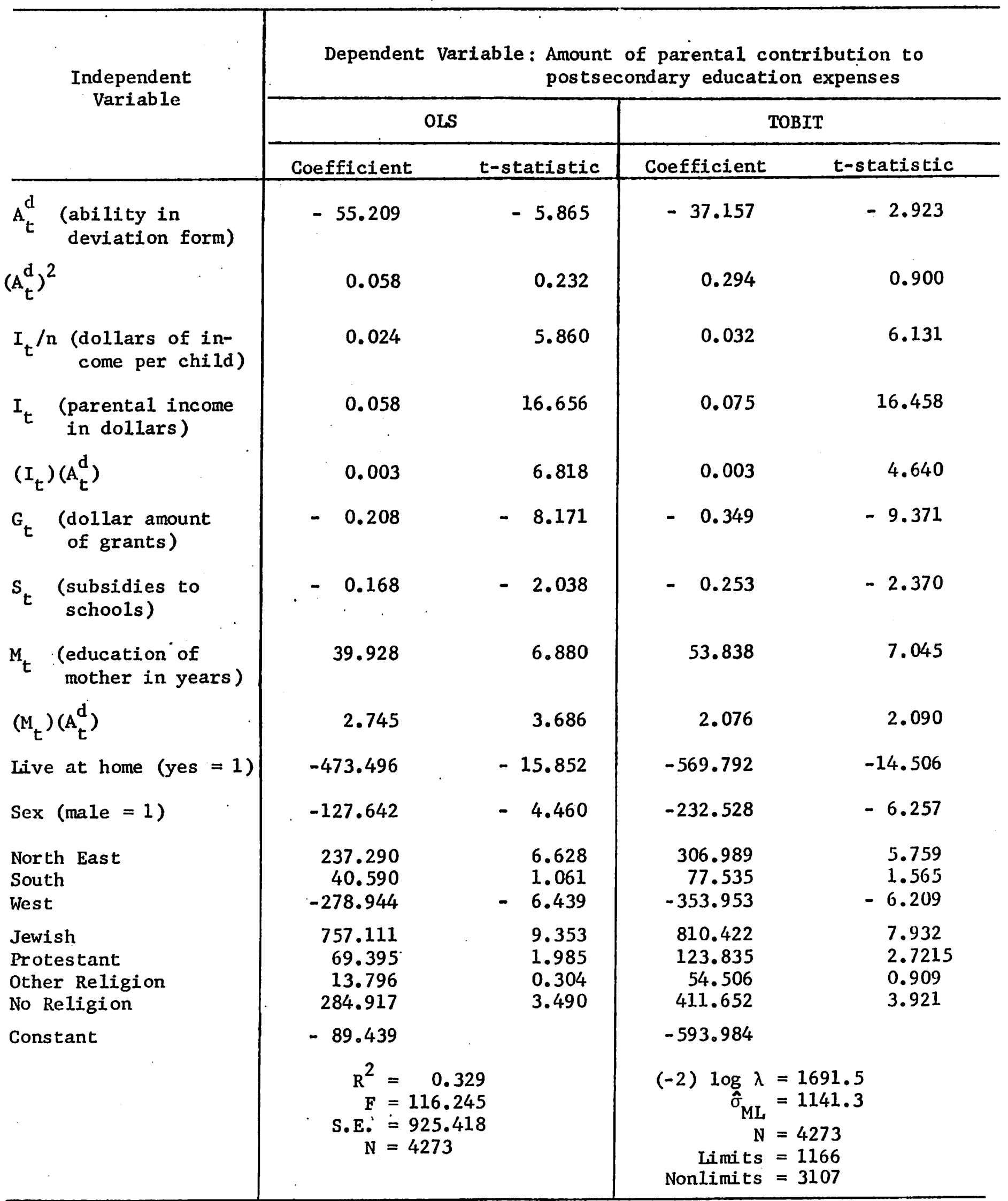


TABLE II

VARIABLE NAMES AND DEFINITIONS

FOR SINGLE STUDENTS ENROLIED IN POST-SECONDARY INSTITUIIONS IN OCTOBER 1972

\begin{tabular}{|c|c|c|c|}
\hline Variable & Definition & Mean & $\begin{array}{l}\text { Standard } \\
\text { Deviation }\end{array}$ \\
\hline $\mathbf{Q}$ & $\begin{array}{l}\text { The amount of financial support received } \\
\text { from parents or relatives (in dollars) }\end{array}$ & $860.577 *$ & $1127.942 *$ \\
\hline $\begin{array}{l}A^{d} \text { (in devia- } \\
\text { tion form) }\end{array}$ & $\begin{array}{l}\text { The mean of the individual's standardized } \\
\text { scores on mathematics, reading, vocabulary, } \\
\text { and letter groups }\end{array}$ & 0.000 & 7.022 \\
\hline I & Before tax income of parents (in dollars) & 12500.468 & 5294.581 \\
\hline G & $\begin{array}{l}\text { The amount of scholarships or grants re- } \\
\text { ceived from government or non-government } \\
\text { sources (in dollars) }\end{array}$ & $241.387 *$ & $583.714 *$ \\
\hline s & $\begin{array}{l}\text { Per student subsidy given to institutions } \\
\text { of higher education (defined as total } \\
\text { relevant expenditures minus tuition and } \\
\text { fees divided by the number of students in } \\
\text { the state) }\end{array}$ & 1138.748 & 174.781 \\
\hline M & $\begin{array}{l}\text { Number of years of schooling of indi- } \\
\text { vidual's mother }\end{array}$ & 12.417 & 2.765 \\
\hline Live at home & $\begin{aligned} \text { Dummy }= & 1 \text { if student is living at home } \\
& . \text { with parents or relatives }\end{aligned}$ & 0.488 & 0.499 \\
\hline Sex & Dummy $=1$ if individual is male & 0.527 & 0.499 \\
\hline North East & Dummy $\doteq 1$ if high school in North East & 0.236 & 0.424 \\
\hline South & Dummy $=1$ if high school in South & 0.304 & 0.450 \\
\hline West & Dummy = 1 if high school in west & 0.185 & 0.389 \\
\hline Jewish & Dummy $=1$ if individual is Jewish & 0.036 & 0.187 \\
\hline Protestant & Dumny $=1$ if individual is Protestant & 0.450 & 0.497 \\
\hline $\begin{array}{l}\text { Other } \\
\text { Religion }\end{array}$ & $\begin{array}{c}\text { Dummy }=1 \text { if not Protestant, Jewish or } \\
\text { Catholic }\end{array}$ & 0.164 & 0.370 \\
\hline No Religion & Dummy $=1$ if individual has no religion & 0.034 & 0.183 \\
\hline
\end{tabular}

* Computation of mean and standard deviation excludes those individuals who received zero amount. 